\title{
Obstacles to Teaching Mathematics in Middle School for Female Students with Learning Difficulties
}

\author{
Author: Nourah Amro Al-Alweet \\ Mathematics Teacher, Ministry of Education, Kingdom of Saudi Arabia \\ Email: nla814@gmail.com
}

\begin{abstract}
This study aimed to identify the obstacles to teaching mathematics among female students with learning difficulties in the intermediate stage, and to achieve the objectives of the study, the descriptive survey method was used, and the researcher used the questionnaire as a tool for her study, and the study sample consisted of (240) teachers who were randomly selected.

The study found a set of results, the most notable of which are the following: There is broad agreement among mathematics teachers on the obstacles they face when teaching mathematics to students with learning difficulties, where school and organizational obstacles come first, followed by obstacles to mathematics curriculum content, and third. Obstacles to evaluation come, and in the end the obstacles to teaching methods and appropriate qualification are the least obstacles that face female teachers of mathematics when teaching mathematics to students with learning difficulties for the intermediate stage, and the results showed that there is agreement to a large degree among the teachers of learning difficulties on the obstacles they face when teaching mathematics to female students Learning difficulties for the intermediate stage, where the obstacles related to the curriculum content for mathematics come first, followed by the school and organizational obstacles, and in the third rank are the obstacles to teaching methods and appropriate qualification,
\end{abstract}


and in the last place the evaluation obstacles are the least obstacles that face teachers with learning difficulties when teaching mathematics to students with learning difficulties for the stage The mean, and the results also showed that there were differences between me The averages of the responses of the study members about the obstacles to teaching methods and the appropriate qualification that face female teachers of sports and learning difficulties in teaching mathematics for students with learning difficulties in the middle stage according to the different teaching location variable, in favor of the learning difficulties teachers.

Keywords: disabilities, mathematics, teaching, learning difficulties.

\section{1- Introduction:}

The field of learning difficulties is important in the field of special education. This is to provide support for students with learning difficulties, provide them with educational opportunities, and work to help them better integrate into the society in which they live.

Learning difficulties are among the problems that concern many researchers in the educational field in all countries of the world. Students with learning difficulties have normal or extraordinary mental abilities, and yet they show a decline in their academic performance in some academic subjects. Where the gap appears in their academic achievement compared to their colleagues of the same grade and age. Learning difficulties do not disappear with the development of the individual, but the type and severity of the difficulty vary from one age stage to another, and the crisis of this group often intensifies in adolescence, which is the age compatible with the stage of middle and secondary education, as it is difficult for students with learning difficulties at this stage. Adapting to the rapid growth occurring at this age, and carrying out its academic and social requirements, and they may exhibit features of lack of self-confidence, lack of attention, and others. Perhaps one of the reasons for dropping out of school is their inability to fulfill the requirements of this stage. (Hallahan, James, Lloyd, Weiss, and Martis, 2007). 
Teaching mathematics to students with learning difficulties represents a challenge for teachers of learning difficulties, as teaching mathematics requires special skills and competencies, given its density as an intermediate school course, and its need for great effort during the process of teaching ordinary students; Therefore, it takes twice as many skills and effort when teaching students with learning disabilities. This is due to the nature and characteristics of students with learning difficulties, and this is shown by a study (Al-Qudah; Najm, 2009).

Among the obstacles facing mathematics teachers when teaching mathematics to ordinary students: the school and organizational environment, the curriculum content for the mathematics subject, and evaluation. Therefore, the current study focused on revealing obstacles to teaching female students with learning difficulties in intermediate school mathematics, and the impact of this problem on the learning and education of intermediate school students. In light of the above, the idea of this study came to identify the obstacles to teaching mathematics for female students with learning difficulties in the middle school stage.

\subsection{The Study Problem:}

The problem of the study revolves around monitoring the obstacles to teaching among mathematics teachers and teachers with learning difficulties. The study problem can be identified by answering the main question: What are the obstacles to teaching mathematics among students with learning difficulties in middle school?

\subsection{Study Questions:}

The current study tried to answer the following sub-questions:

1. What are the obstacles that face female teachers of mathematics in teaching mathematics to female students with learning difficulties for the intermediate stage with which the learning difficulties programs are attached to the regular class? 
2. What are the obstacles that face female learners with learning difficulties in teaching mathematics to female students with learning difficulties in the intermediate stage with which the learning difficulties programs are attached to the resource room?

3. Are there statistically significant differences in the obstacles facing female teachers of mathematics and teachers of learning difficulties in teaching mathematics to female students with learning difficulties in the intermediate stage attached to the learning difficulties programs according to the place of teaching (regular classroom - resource room)?

4. Are there statistically significant differences in the obstacles facing female teachers of mathematics and teachers of learning difficulties in teaching mathematics to female students with learning difficulties in the intermediate stage attached to the learning difficulties programs according to the variable (years of experience)?

\subsection{Study Objectives:}

1. Identify the obstacles that face female teachers of mathematics in teaching mathematics to female students with learning difficulties in the intermediate stage with which the learning difficulties programs are attached in the regular class.

2. Identify the obstacles that face female teachers with learning difficulties in teaching mathematics to female students with learning difficulties in the intermediate stage attached to the learning difficulties programs in the resource room.

3. Identify the statistically significant differences of the obstacles facing female teachers of mathematics and teachers of learning difficulties in teaching mathematics to students with learning difficulties in the intermediate stage to which the learning difficulties programs are attached according to the place of teaching (regular classroom, resource room). 
4. Identify the obstacles that face female teachers of mathematics and teachers of learning difficulties in teaching mathematics to students of learning difficulties in the intermediate stage to which the learning difficulties programs are attached according to the variable (years of experience).

\subsection{The Study Importance:}

The theoretical and practical importance is as follows:

First: Theoretical Importance: The theoretical importance is as follows:

The importance of this study lies in revealing the obstacles to teaching mathematics for women with learning difficulties in the intermediate stage attached to the learning difficulties programs, in order to facilitate the teaching process and advance the level of students with learning difficulties in mathematics.

- The researcher hopes that this study will contribute to drawing the attention of educators, researchers, and mathematics teachers, in order to know the nature of the problems of teaching female students with learning difficulties.

- This study may contribute to looking at the practices of teaching teachers with students with learning difficulties. This achieves integration and cooperation between special education teachers and public education teachers.

Second: Application Importance: The application importance is as follows:

This study may assist decision-makers in conducting appropriate training courses for female teachers. It contributes to raising the level of female students with learning difficulties to the desired level.

- This study may help in reviewing the teaching methods and appropriate strategies for mathematics for female students with learning difficulties and their evaluation method.

\subsection{The Study Limitation:}

The study limits are represented in the following limits: 
Objective limitations: This study was limited to the subject of obstacles to teaching female students with learning difficulties in the subject of mathematics at the intermediate level, to which the programs of learning difficulties are attached.

Time limits: This study was applied during the second semester of the academic year 1439/1440 AH.

Spatial boundaries: The application of this study was limited to middle school schools attached to the learning difficulties programs in the city of Riyadh.

Human Limits: This study was limited to the teachers of learning difficulties in the resource room in the intermediate stage, and to the teachers of mathematics in the regular class in the intermediate stage to which the learning difficulties programs are attached, and that is in the second semester of the academic year 1439/1440 AH.

\subsection{Study Terminology:}

\section{Obstacles:}

Obstacles and difficulties faced by female teachers of learning difficulties and female teachers of mathematics in teaching mathematics to female students with learning difficulties and are measured through their response to the questionnaire.

\section{Learning difficulties:}

A marked decrease in academic achievement among a group of female students compared to their ordinary classmates in the intermediate stage, even though they have normal and above-average intelligence, and they show difficulties in some learning processes, but they are not among those with an intellectual disability or any other disability.

\section{Female students with learning difficulties:}

Female students enrolled in the resource room and received inside the resource room in proportion to their abilities and needs by teachers who specialize in learning difficulties, during part of the school day. 


\section{Intermediate stage:}

The stage that follows the primary stage and precedes the secondary stage, and includes grades: first, second, and third intermediate in schools affiliated with the Ministry of Education in the Kingdom of Saudi Arabia.

\section{Theoretical Framework:}

The current era is witnessing rapid changes in various fields, which imposes a burden on the institutions of society to prepare a generation that can deal effectively with these changes, and we find that educational institutions are among the most important of these institutions, so a large part of this burden falls on their shoulders. Mathematics is the cornerstone of development that takes place in various fields and fields, and therefore school mathematics curricula must be developed in such a way as to eliminate the gap between what the student learns inside and outside school so that the learner realizes the extent of the benefit from learning mathematics in solving his problems.

Learning difficulties in mathematics are a very important aspect in the field of learning difficulties, but attention to these difficulties came relatively late, as most research and studies focused in the past on reading and writing difficulties, and few focused on mathematics difficulties (Sawalha, 2011).

The first axis: learning difficulties in the field of mathematics.

\section{The concept of mathematics learning difficulties:}

It is a disorder of the ability to learn mathematical concepts and perform the associated mathematical operations. It is also known as difficulty or inability to perform basic arithmetic operations, namely: addition, subtraction, multiplication, division, and the consequent problems in studying fractions, algebra, and geometry later (Hafez, 2008). 
Al-Zayat (2012) believes that learning difficulties in mathematics are a term that expresses difficulties or difficulties in using and understanding mathematical facts, computational understanding, numerical and mathematical reasoning, conducting and processing mathematical and mathematical operations.

\section{What is mathematics?}

Perhaps one of the most difficult questions that can be directed to a specialist in mathematics or someone interested in it is the question: What is mathematics? The mathematical philosophers who devoted their lives to answering this question did not arrive at a definite agreed answer, which leads to the saying that there is a crisis in mathematical thought as a result (Mina, 2007).

Al-Mughira (2008) states that there is no acceptable definition of mathematics for everyone. Mathematics means different things for different people, and it is a subject that develops over time.

Ancient mathematics differs from modern mathematics. So mathematician Poincare said to her that she is giving the same name to many different things.

\section{Objectives of Teaching Mathematics:}

1. Forming the modern mathematical basis of concepts, facts, terms, symbols, and basic treatment methods, which gives the citizen a comprehensive mathematical culture and lays the building blocks on which his studies can be based in the following educational stages.

2. Realizing that mathematics is a living and renewable material that the student can participate in making it, discover the relationships inherent in it, and create evidence to generalize it and that the mathematical truth is a relative reality that depends mainly on the assumptions and axioms on which it is built.

3. Gain skill in dealing with quantitative problems and analyzing statistical data intelligently and consciously.

4. Show the role of mathematics in contributing to solving development problems in the Arab world. 
5. Contributing to the formation of an aware scientific readiness for the planned life problems in an attempt to solve them in the best and easiest way.

6. Developing the ability to discover and innovate and accustom the student to the process of abstraction and generalization.

7. Acquiring sound social attitudes and habits such as objectivity in thinking, accuracy in expression, ability to organize and work purposefully, and to use planning and design methods to solve mathematical and non-mathematical problems.

8. Highlight the importance of mathematics not only in the natural sciences but also in social, behavioral, economic, and other human activities.

\section{Types of mathematics learning difficulties for students with learning disabilities:}

First: Difficulties in learning pre-mathematical skills:

Some students may have difficulty identifying similar shapes and distinguishing different shapes.

Some students may have difficulty identifying spatial relationships, such as up, down, right, and left front, and back.

Second: Difficulties learning numbers and arithmetic operations:

Some students may have difficulty distinguishing between $(2,6)$ and $(7,8)$.

Some students may encounter difficulty in counting unordered objects in a picture or drawing.

Some students may have difficulty distinguishing between $(+,-)$ and $(\div, \mathrm{x})$ arithmetic operations.

Third: Difficulties in learning to engineer:

Some students may not be able to construct and distinguish the figures.

Fourth: Difficulties learning measurement: 
Some students may start measuring the lengths of objects using the ruler from number 1.

Students may not be able to collect different units of money together (piasters, dirhams, and dinars).

Fifth: Difficulties in learning to solve a mathematical problem:

- Students may not be able to determine the appropriate arithmetic operation to solve a mathematical problem, so the student poses the question to the teacher: Do we add or subtract?

Students may not be able to develop a suitable plan for solving a mathematical problem.

Abd al-Hadi and others (2010) add that there are several types of mathematical difficulties that students with learning disabilities face, the most important of which are:

1. Failure completely in mathematics, and this means that all mathematical skills are unsound and have not developed a readiness for the student to learn mathematics.

2. A partial decline in all mathematical skills to the same degree. The student gets low results in relation to the results expected of his generation.

3. Some of the mathematical skills have failed, so that the other part of the skills is healthy and free from defects.

Factors affecting teaching students with learning difficulties mathematics:

1. Difficulties in mastering basic mathematical numerical facts:

2. Difficulties with simple arithmetic skills:

3. The concept of numbers:

4. Difficulties learning the language of mathematics:

5. Difficulties with counting: 
6. Difficulties of solving a verbal mathematical problem:

7. Difficulties in the visual-spatial perception of geometric shapes.

\section{Characteristics of students with mathematics learning difficulties:}

Students with learning difficulties appear to have mathematics learning difficulties in the following:

1. Has difficulty learning mathematical and mathematical concepts.

2. He encounters difficulty in performing mathematical operations such as addition, subtraction, division, and multiplication.

3. Common mistakes in reading, writing, and retrieving numbers, such as addition, subtraction, division, and multiplication.

4. Weakness in digital memory, which emerges from the inability to memorize and remember mathematical concepts, arranging and performing arithmetic operations, and the facts of addition, subtraction, multiplication, and division.

5. Difficulty in understanding lengths, areas, and volumes, which is difficult for him to estimate.

6. Difficulty adding, subtracting, and dividing decimals.

7. Difficulty converting between units of lengths, areas, and volumes (Al-

Batayneh and Al-Rashdan, 2015).

\section{Manifestations of Mathematics Learning Difficulties among Students With}

\section{Learning Difficulties:}

1. Difficulty distinguishing sizes.

2. Difficulty distinguishing shapes.

3. The difficulty of distinguishing the value of the place of the number.

4. Difficulty with mathematical skills.

5. Failure to orally understand mathematical problems. 
6. Failure to read mathematical symbols correctly (numbers and arithmetic relationships, understanding their significance, and difficulty pronouncing them.)

7. The difficulty of writing mathematical numbers and mathematical symbols correctly and confusing them.

8. The difficulty in producing geometric shapes.

9. Take a long time to organize your thoughts.

10. Difficulties in life arithmetic, such as difficulty dealing with money to buy, move, or recognize trends.

11. Abstract arithmetic difficulties: It means the difficulty in applying laws and theories such as performing addition or subtraction operations on the integer numbers.

In general, these manifestations can be divided into:

First: Difficulties related to cognitive processes: These difficulties, as identified by Al-Faouri (2010), refer to the following problems:

1. Attention problems: Many students with learning difficulties suffer from many mathematical errors, such as retrieval errors or procedural errors due to the difficulty in retrieving mathematical facts or the difficulty of performing mathematical operations, not because of special difficulty, but because of the difficulty of attention.

2. A deficiency in perception: which appears in the inability to distinguish between shapes, sizes and distances, and written and audible words, especially when the differences are subtle, such as the distinction between the shapes of numbers, the shape of a square or a rectangle, or between lines and areas of shapes.

3. Memory problems: These problems vary according to different types of memory. In short memory, students with learning difficulties are unable to retain facts or new information and forget the solution steps. In long memory, these individuals suffer from important educational problems in learning basic facts, 
As in the multiplication table, which they master only very slowly and over a long period.

4. Disturbances in thinking strategies: Among the manifestations of this are:

Difficulty adhering to the different steps of solving mathematical problems.

Difficulty following a single series of solution ideas, which leads to failure to adhere to the solution strategy.

He finds it difficult to plan, that is, he cannot plan well for the tasks or duties assigned to him, and suffers from problems in the transition from sensory thinking to abstract thinking.

He finds it difficult to deal with mathematical symbols in addition to his poor experience with numbers such as 4 is less than 100 .

He finds it difficult to form mathematical concepts or understand the relationships between them, such as performing mental mathematical operations.

He finds difficulties in arranging numbers in terms of size, and problems with correct counting, such as 16 before 17 .

Second: Difficulties related to academic performance in mathematics: Among its manifestations: Ali (2011):

Reading difficulties: which are directly related to reading skills related to sports tasks, including:

He finds it difficult to recognize and use arithmetic symbols, such as addition, subtraction, division and multiplication.

He has difficulty reading numbers that contain more than one digit, especially those with zeros.

Has distortion in the direction of reading, such as reading numbers backwards so that 12 reads 21 .

Confusion in reading similar numbers, problems reading charts, tables and graphs. 
Writing difficulties: which are directly related to writing skills related to mathematical tasks, including:

Writing symbols, often numbers (where he writes them backwards or upside down), problems copying numbers, results, or geometric figures from a blackboard, book, or picture, problems with retrieving numbers, results, arithmetic operations, or geometric shapes from memory to write them, as well as He finds it difficult to remember the meaning of mathematical symbols.

There is a set of tools used to diagnose learning difficulties, including:

\section{Case study:}

Through it, information expressing the history of the person under study is collected and data are collected on certain aspects that constitute the interest of the subject of study.

\section{Achievement tests:}

To identify those students who are in need of more services, schools screen large groups of students in mathematics.

\section{Mental ability tests:}

(Khairy, 2008) mentioned a set of tests that measure the following:

a. Linguistic ability (synonym, contrast, meaning of concept, concept distinction).

B. Numerical ability (the four arithmetic operations, the relationship of numbers to each other, arithmetic inference).

T. Spatial ability (distinguishing shapes, positioning shapes, relationship of shapes with each other, comparison of shapes, sizes of shapes).

D. Inference ability (computational reasoning, linguistic reasoning, spatial reasoning).

C. The ability to perceive relationships (between words, numbers, and shapes). 


\section{Scale of estimating the behavioral characteristics of people with learning difficulties:}

The scale dimensions consisted of: Attention deficit - hyperactivity impulsivity - emotional fluctuation - poor social compatibility and behavioral characteristics common to those with learning difficulties, some of which may be common to most students and some of them are of severe degree, and some of them exist at a moderate or mild degree.

The second axis: teaching problems for students with learning difficulties:

\section{Teaching mathematics to students with learning difficulties:}

Effective teaching methods depend on three main theoretical orientations, which are the most used approaches in education in general and teaching students who have learning difficulties in particular. These trends are behavioral theories, cognitive theories, and social learning theories (Abunyan, 2015).

First: Direct Teaching: Direct teaching has clear characteristics that can be summarized as follows (Abu Nayan, 2015):

Follow a clear strategy with incremental steps, one by one.

- To develop mastery in every step of teaching while learning.

Correcting the student's mistakes through a specific strategy.

- Gradual transition from teaching that depends on directing the teacher to the student's work independently.

Use adequate practice and exercises with various examples.

A cumulative review of newly learned concepts.

Second: Diagnostic Teaching: Diagnostic teaching is an attempt to determine the most effective teaching strategies in teaching students who have learning difficulties, and it is based on four important assumptions, namely (Gordon, 2009): The student comes to the position of learning with weaknesses and strengths. 
There is a relationship, albeit not strong, between the strengths and weaknesses of students and the acquisition of academic skills.

Weaknesses and strengths can be diagnosed truthfully and consistently.

There is an accessible link between strengths and weaknesses and the relative effectiveness of teaching.

Third: Accurate Teaching: Accurate teaching is a set of procedures that help the teacher analyze behavior changes in students 'performance. Accurate teaching is a method for evaluating the curriculum and teaching method used by the teacher.

The teacher's study of student behavior is the best way to provide information about the student.

The response frequency is the general measure of behavior.

- Student performance should be depicted on a graph.

Focus on continuous direct monitoring of students' performance.

Procedural description and response to behavior and response.

Focus on building the behavior rather than eliminating or eliminating it.

Analyzing the impact of environmental influences on behavior.

The role of teachers with students with learning difficulties.

- Ensure that students learn the requirements and previous skills in mathematics.

- Teaching should be based on awareness of students' strengths and weaknesses.

- Building solid foundations for mathematical concepts and skills.

- Present arithmetic operations in a tangible way, such as addition, subtraction, multiplication, and division.

\section{Previous Studies:}

Al-Assimah and Al-Sharaa (2019) conducted a study aimed at investigating obstacles to mathematics education among students of the first three grades from the viewpoint of teachers and educational supervisors. 
The two researchers used a mixed methodology (quantitative-qualitative). The sample consisted of (160) teachers and (18) educational supervisors in the governorate of Karak, and the tool was a questionnaire consisting of (76) items.

The results of the study showed that the female teachers saw the obstacles related to the student came first and that the least obstacles to mathematics education were related to the curriculum. While the educational supervisors saw that the most obstacles to mathematics are related to the student and that the family is rarely an obstacle to teaching mathematics, as it came in the last order, and in light of the results, the study recommended a set of recommendations.

Ziad (2017) conducted a study aimed at researching the factors leading to learning difficulties in the subject mathematics and its most common elements, and to find out if these factors differ according to the variables gender and the research to the nature of the study, to the nature of the study, and the nature of the study. Applying the tool represented in "a questionnaire of factors leading to difficulties learning in mathematics, and applying basic study in some high schools in the city of Ouargla on a sample of (200) students of the third year in secondary schools. The results of the study resulted in finding the factors that lead to the learning difficulties in the subject mathematics of the third secondary students (teacher, curriculum, learner ) and the most prevalent ones, and that these factors do not differ in the specialization different in their gender.

The study of Traf and Skaggerland (Traff \& Skaggerlund, 2016) indicates the identification of the nature of cognitive difficulties in mathematics among various groups of people with learning difficulties, and the experimental approach was used to achieve the objectives of the study. The study sample consisted of two groups of people with learning difficulties: the first group had a learning difficulty. Basic arithmetic skills, while the second group of children suffers from difficulty learning mathematics in general, and the study tools were represented by a group of cognitive tests, 
and the results of the study indicated that there is a marked weakness in preparing and processing numbers when presented symbolically by students of the first group who suffer difficulties in Learning basic mathematical skills, while there is a marked weakness in preparing and processing numbers when presented in a symbolic or non-symbolic manner among students of the second group who suffer from learning difficulties in mathematics in general,

And the researchers interpreted these results that the disorder among students of the first group was in the process of perceiving the symbolic form The number while the disorder in the pupils of the second group in the numerical system as a whole.

The study of Al-Juhani and Al-Zari (2014) sought to identify the obstacles that face teachers of students with learning difficulties using educational aids in teaching reading and to develop proposals that contribute to reducing them in the use of these methods. The two researchers used the descriptive approach, and the study was conducted on a sample consisting of (72) male and female teachers in the Al-Madinah Al-Munawwarah region and Yanbu Al-Bahr, who study students with learning difficulties. To achieve the objectives of the study, a tool was used to reveal the obstacles that face the use of teachers of students with learning difficulties and educational aids in teaching reading, and the most important findings of the study showed that obstacles are facing the use of teachers of students with learning difficulties in the field of audio-visual aids. Moderate, while the educational aids, visual aids, and the techniques and devices that were highly specific for each of them were obstacles. The results also showed that there are statistically significant differences in the average response of teachers of students with learning difficulties towards obstacles to using educational aids in teaching reading for the benefit of male teachers, and the absence of a statistically significant difference for any of the two variables of academic qualification and experience. The researchers recommended designing reading activities that use educational aids in teaching reading that take into account the different learning styles of students with learning difficulties. 
The study of Al-Thubaiti (2011) dealt with determining the difficulties of solving verbal mathematical problems of fourth-grade female students from the point of view of mathematics teachers and supervisors in the elementary stage in Taif. In the primary stage in (145) public primary schools in Taif, Kingdom of Saudi Arabia.

The researcher used the questionnaire as a tool to collect information, and the study reached a set of results, the most important of which are: The difficulties of solving verbal mathematical problems resulting from subjective factors included: difficulties reading and understanding the verbal mathematical problem, difficulties in representing the verbal mathematical problem, planning difficulties to solve the verbal mathematical problem, and difficulties in implementing the solution of the problem. Verbal mathematics, and difficulties in verifying the correctness of the solution. The difficulties of solving the verbal mathematical problem related to the nature of the verbal mathematical problems were of a moderate degree.

Takbir's study (2011) aimed to identify how high school teachers while teaching mathematics, try to use remedial educational programs to help students overcome the difficulties of learning mathematics at the secondary level in India. The study used the descriptive approach and the study sample consisted of (4) secondary school teachers in the Baltistan region in India, and the study used interviews, class notes, and analysis of test content as tools to collect information, and the study reached a set of factors that prevent students' in-depth understanding of mathematics topics, the most important of which is the potential to enhance learning. In-depth by identifying the teacher's priority in bridging the gap between students' cognitive thinking and knowledge of mathematics topics.

The study also emphasized the great importance of students 'previous knowledge of basic mathematical concepts in promoting in-depth learning of new concepts in addition to the instructional actions and decisions made by teachers and their impact in enhancing students' learning of mathematics topics. 
Tambychik's study (2010) aimed to discuss mathematics skills and cognitive abilities of students that cause difficulties in solving mathematics problems from the students' point of view. The study was applied to three focused samples that were deliberately chosen. The questionnaire and interviews were used as tools to collect information.

The results of the study showed that the study sample lacked many mathematics skills, such as numerical facts skills and visual-spatial ability, and that a deficiency in these skills prevented students from being able to solve mathematical problems, and the study showed that the difficulties students face as a result of the lack of these skills give lines An effective guideline in preparing the necessary diagnostic tools to develop the necessary mathematics skills to enhance students' ability to overcome the difficulties of solving mathematical problems.

\subsection{General comment on previous studies:}

1. The current study meets some previous studies in dealing with the problems of teaching mathematics to students with learning difficulties, such as the study of Ali and Abdul Hakim (2013) and Yusef (2013). It differs from previous studies in that it seeks to uncover problems in the regular classroom and the resource room. The current study also meets the previous studies in dealing with the intermediate stage, such as the study of the immune system (2016), and the study of Zen et al. (Xin et al, 2009), but it differs from the current study in the study population and its sample.

2. The current study used the descriptive survey approach to achieve the objectives of the study and agreed with many previous studies such as the study of Al-Juhani and Al-Zari (2014), Ali and Abdul Hakim's study (2013), Al-Thubaiti study (2011), Al-Mujeedel study (2007), all of which were used. Descriptive approach in achieving the objectives of the study. On the other hand, the current study differed in the methodology used with some other studies such as the study of Traf and Skaggerland (Traff \& Skaggerlund, 2016), 
The study of Costa and others ((Costa et al, 2015), as this study adopted the experimental approach in achieving the objectives of the study.

This study was distinguished from others by being the first study that dealt with the obstacles to teaching female students with learning difficulties in middle school in the Kingdom of Saudi Arabia, as well as that it brought together the teachers of mathematics who study students with learning difficulties and the teachers of learning difficulties as individuals of the sample, and this study was distinguished by that it highlighted the obstacles that Mathematics teachers and learning difficulties teachers have in common when teaching mathematics to female students with learning difficulties, and this study was conducted in Riyadh, and this study also differs with other previous studies in its limits: spatial, temporal, objective, and human.

\section{Study Methodology:}

\subsection{Study Approach:}

In this study, the researcher used the descriptive survey method to answer the study questions, by uncovering the teaching obstacles of the learning difficulties teachers and the mathematics teachers in the schools attached to the governmental learning difficulties programs.

\subsection{Study Population:}

The study population consisted of all the teachers of learning difficulties and mathematics teachers in the schools attached to the learning difficulties programs for the intermediate stage for girls, affiliated to the Riyadh City Education Department, which numbered: (76) schools with a total of (468) teachers of learning difficulties and mathematics teachers (Riyadh Education Department, $1439 \mathrm{AH})$. 
Table (1)

Distribution of the study population according to the nature of work

Teachers of learning difficulties

151
The number of math parameters

\subsection{The Study Sample:}

The study sample consisted of a random sample consisting of (240) teachers of learning difficulties and mathematics teachers in public schools attached to the learning difficulties programs in the city of Riyadh,

According to the schedule of Chrissy and Morgan (Krejcie \& Morgan). The amount of (468) is (214), and the researcher distributed (250) questionnaires to the female teachers. (243) teachers responded with her, and (3) incomplete questionnaires were excluded. The researcher used them all for scientific honesty, and to save the efforts of the respondents.

Table (2)

Study sample according to society

\begin{tabular}{|c|c|c|c|c|c|}
\hline $\begin{array}{c}\text { Work } \\
\text { nature }\end{array}$ & $\begin{array}{c}\text { Study } \\
\text { population }\end{array}$ & $\begin{array}{c}\text { the } \\
\text { percentage }\end{array}$ & $\begin{array}{c}\text { Sample } \\
\text { according } \\
\text { to the } \\
\text { equation }\end{array}$ & $\begin{array}{c}\text { The sample } \\
\text { is according } \\
\text { to the } \\
\text { proportion } \\
\text { in the } \\
\text { sample }\end{array}$ & $\begin{array}{c}\text { Completed } \\
\text { responses }\end{array}$ \\
\hline $\begin{array}{c}\text { A teacher } \\
\text { with } \\
\text { learning } \\
\text { difficulties }\end{array}$ & 151 & 32.3 & 214 & 69 & 71 \\
\hline $\begin{array}{c}\text { Math } \\
\text { teacher }\end{array}$ & 317 & 67.7 & 214 & 145 & 169 \\
\hline Total & 468 & 100.0 & - & 214 & 240 \\
\hline
\end{tabular}




\subsection{Study Tool:}

Based on the nature of the data, and the approach followed in the study, the researcher found that the most appropriate tool to achieve the objectives of this study is the "questionnaire".

\subsubsection{Tool Validation:}

The researcher verified the validity of the instrument (the questionnaire) through the following:

First: the apparent validity of the study tool (validity of arbitrators):

After completing the construction of the study tool, which deals with "obstacles to teaching female students with learning difficulties in intermediate school mathematics", it was presented to a number of arbitrators (10) for the guidance of their opinions.

\section{Second: Validity of the internal consistency of the study tool:}

After confirming the apparent validity of the study tool, the researcher applied it in the field to an exploratory sample consisting of (35) teachers from the two categories (normal - learning difficulties). On the sample data, the researcher calculated the correlation coefficient, Pearson to find out the internal validity of the questionnaire, where the correlation coefficient was calculated between the degrees of each a statement of the resolution statements with the total degree of the axis to which the statement belongs, as shown in the following tables:

Table (3)

Pearson correlation coefficients for axes expressions (constraints faced by parameters at teaching mathematics to female students with learning difficulties) for each statement

\begin{tabular}{|c|c|c|c|c|c|c|c|}
\hline \multicolumn{2}{|c|}{$\begin{array}{c}\text { School and } \\
\text { organizational obstacles }\end{array}$} & $\begin{array}{c}\text { Curriculum content } \\
\text { constraints for } \\
\text { mathematics }\end{array}$ & \multicolumn{2}{c|}{$\begin{array}{c}\text { Assessment } \\
\text { Constraints }\end{array}$} & \multicolumn{2}{c|}{$\begin{array}{c}\text { Obstacles to } \\
\text { teaching methods } \\
\text { and rehabilitation }\end{array}$} \\
\hline Phrase & $\begin{array}{c}\text { Correlation } \\
\text { coefficient }\end{array}$ & Phrase & $\begin{array}{c}\text { Correlation } \\
\text { coefficient }\end{array}$ & Phrase & $\begin{array}{c}\text { Correlation } \\
\text { coefficient }\end{array}$ & $\begin{array}{c}\text { Phrase } \\
\text { Correlation } \\
\text { coefficient }\end{array}$ \\
\hline 1 & $* * 0.821$ & 1 & $* * 0.572$ & 1 & $* * 0.531$ & 1 & $* * 0.772$ \\
\hline 2 & $* * 0.457$ & 2 & $* * 0.723$ & 2 & $* * 0.689$ & 2 & $* * 0.765$ \\
\hline 3 & $* * 0.656$ & 3 & $* * 0.739$ & 3 & $* * 0.720$ & 3 & $* * 0.605$ \\
\hline
\end{tabular}




\begin{tabular}{|c|c|c|c|c|c|c|c|}
\hline 4 & $* * 0.729$ & 4 & $* * 0.519$ & 4 & $* * 0.785$ & 4 & $* * 0.678$ \\
\hline 5 & $* * 0.700$ & 5 & $* * 0.601$ & 5 & $* * 0.640$ & 5 & $* * 0.758$ \\
\hline 6 & $* * 0.714$ & 6 & $* * 0.557$ & 6 & $* * 0.722$ & 6 & $* * 0.866$ \\
\hline 7 & $* * 0.593$ & 7 & $* * 0.530$ & 7 & $* * 0.616$ & 7 & $* * 0.639$ \\
\hline 8 & $* * 0.572$ & 8 & $* * 0.628$ & 8 & $* * 0.820$ & 8 & $* * 0.832$ \\
\hline 9 & $* * 0.586$ & 9 & $* * 0.777$ & - & - & - & - \\
\hline- & - & 10 & $* * 0.626$ & - & - & - & - \\
\hline- & - & 11 & $* * 0.638$ & - & - & - & - \\
\hline
\end{tabular}

\subsubsection{Stability of the study tool:}

The researcher measured the reliability of the study using the Cronbach alpha stability factor, and Table No. (4) Shows the reliability coefficient for the study tool axes as follows:

\begin{tabular}{|c|c|c|c|}
\hline No & The Axis & $\begin{array}{c}\text { The number of } \\
\text { phrases }\end{array}$ & Stability coefficient \\
\hline 1 & School and organizational obstacles. & 9 & 0.771 \\
\hline 2 & $\begin{array}{l}\text { Curriculum content constraints for } \\
\text { mathematics. }\end{array}$ & 11 & 0.784 \\
\hline 3 & Assessment Constraints. & 8 & 0.816 \\
\hline 4 & $\begin{array}{l}\text { Appropriate teaching and qualification } \\
\text { methods }\end{array}$ & 8 & 0.881 \\
\hline \multicolumn{2}{|r|}{ Total stability } & 36 & 0.928 \\
\hline
\end{tabular}

It is evident from Table No. (4) that the study scale has statistically acceptable stability, as the value of the overall stability coefficient of Cronbach alpha (0.928) is a high degree of stability, and the stability coefficients of the study tool ranged between $(0.771,0.881)$, which are high stability coefficients. They can be trusted in the application of the current study.

\subsection{The statistical methods used in the study:}

1. Frequencies and percentages: to identify the personal and functional characteristics of the members of the study sample, as well as to determine the 
responses of its members towards the phrases of the main axes that are included in the study.

2. Pearson correlation coefficient: to calculate the validity of the internal consistency of the study tool.

3. Cronbach's Alpha: to calculate the coefficient of stability of the different axes of the study tool.

4. Mean: This is to find out how high or low the responses of the study members are from the main axes (phrase averages), knowing that it is useful for arranging the interlocutors according to the highest arithmetic average.

5. Standard Deviation was used to identify the extent of deviation of the responses of the study individuals for each statement of the study variables, and for each of the main axes, from their arithmetic mean. It is noticed that the standard deviation shows the dispersion in the responses of the study sample individuals to each of the statements of the study variables, in addition to the main axes, so the closer its value is to zero; The more focused the responses, the lower their dispersion between the scale.

6. An Independent Sample T-Test (T) was used for two independent samples to identify the differences in the responses of the study sample individuals towards the study axes according to the different variables of the study, which are divided into two categories (workplace).

\section{Analyze and discuss the results of the study}

The first question: What are the obstacles that face female teachers of mathematics in teaching mathematics to female students with learning difficulties for the intermediate stage with which the learning difficulties programs are attached to the regular class?

In order to identify the obstacles facing mathematics teachers when teaching mathematics to female students with learning difficulties for the intermediate stage with which learning difficulties programs are attached to the regular classroom, the arithmetic averages and the standard deviation were used for the responses of the study sample individuals, as follows: 


\section{Table No. (5)}

Arithmetic averages and standard deviation of the obstacles facing mathematics teachers when teaching mathematics to students with learning difficulties for the intermediate stage to which the learning difficulties programs are attached to the regular semester

\begin{tabular}{|c|c|c|c|c|}
\hline No & Obstacles & $\begin{array}{c}\text { Arithmetic } \\
\text { average }\end{array}$ & standard deviation & ranking \\
\hline $\mathbf{1}$ & $\begin{array}{c}\text { School and } \\
\text { organizational obstacles. }\end{array}$ & 3.54 & 0.41 & 1 \\
\hline & $\begin{array}{c}\text { Curriculum content } \\
\text { obstacles for } \\
\mathbf{2}\end{array}$ & 3.47 & 0.43 & 2 \\
\hline $\mathbf{3}$ & Assessment obstacles. & 3.43 & 0.51 & 3 \\
\hline & $\begin{array}{c}\text { Obstacles to teaching } \\
\text { methods and appropriate } \\
\mathbf{4}\end{array}$ & 3.14 & 0.62 & 4 \\
\hline \multicolumn{2}{|c|}{ general arithmetic mean } & $\mathbf{3 . 4 8}$ & $\mathbf{0 . 3 6}$ & - \\
\hline
\end{tabular}

It is clear from Table No. (5) that the axis of the obstacles that female mathematics teachers face when teaching mathematics to students with learning difficulties for the intermediate stage to which the learning difficulties programs are attached in the regular semester includes four dimensions, which are respectively according to their arithmetic average: (school and organizational obstacles, content obstacles, The curriculum for mathematics, assessment obstacles, obstacles to teaching methods and appropriate qualification), and three dimensions came with a high degree of approval, respectively (school and organizational obstacles, obstacles to the content of the curriculum for mathematics, assessment obstacles), while one dimension came with a medium degree of approval, which is (obstacles). Teaching methods and appropriate qualification), where the arithmetic averages of the dimensions range between $(3.14,3.54)$, which are averages located in the third and fourth categories of the quadruple graduated scale categories, which indicate a degree of agreement (medium-large). 
The results of the current study are in agreement with the results of Abd alGhafour's study (2015), which concluded that there is agreement among mathematics teachers on the difficulties facing the process of learning and teaching mathematics in Kerala state, India. The results of the current study are also in agreement with the results of a study on and Abdul Hakim (2013), which concluded That there is agreement among the study members on the problems of teaching the developed mathematics content at the primary stage in the Kingdom of Saudi Arabia, and the result of the current study agreed with the result of the study of Stefa et al. and teachers in the learning and teaching of mathematics in secondary schools and colleges in the state of Assam, India.

The second question: What are the obstacles that teachers of learning difficulties face when teaching mathematics to students with learning disabilities in the intermediate stage to which the learning difficulties programs are attached to the resource room?

To identify the obstacles facing learning difficulties female teachers when teaching mathematics to female students with learning difficulties for the intermediate stage with which learning difficulties programs are attached to the resource room, arithmetic averages and standard deviation were used for the responses of the study sample individuals, as follows:

Table No. (6)

Arithmetic averages and standard deviation of the obstacles facing teachers of learning difficulties when teaching mathematics to students with learning difficulties for the intermediate stage to which learning difficulties programs are attached in the resource room

\begin{tabular}{|c|c|c|c|c|}
\hline No & Obstacles & $\begin{array}{c}\text { Arithmetic } \\
\text { average }\end{array}$ & standard deviation & ranking \\
\hline $\mathbf{2}$ & $\begin{array}{c}\text { Curriculum content } \\
\text { obstacles for } \\
\text { mathematics. }\end{array}$ & 3.54 & 0.46 & 1 \\
\hline $\mathbf{1}$ & $\begin{array}{c}\text { School and } \\
\text { organizational obstacles. }\end{array}$ & 3.40 & 0.52 & 2 \\
\hline
\end{tabular}




\begin{tabular}{|c|c|c|c|c|}
\hline $\mathbf{4}$ & $\begin{array}{c}\text { Appropriate teaching } \\
\text { and training methods. }\end{array}$ & 3.40 & 0.66 & 3 \\
\hline $\mathbf{3}$ & Assessment obstacles. & 3.35 & 0.46 & 4 \\
\hline \multicolumn{2}{|c|}{ general arithmetic mean } & 3.43 & 0.41 & - \\
\hline
\end{tabular}

It is evident from Table No. (6) that the axis of the obstacles that face the teachers of learning difficulties when teaching mathematics to female students with learning difficulties for the middle stage with which the learning difficulties programs are attached to the resource room includes four dimensions, which are respectively according to their arithmetic mean: (Curriculum content constraints for mathematics. school and organizational, obstacles to teaching methods, and appropriate qualification (obstacles to assessment).

All of them came with a significant degree of agreement, where the arithmetic averages of the dimensions range between $(3.35,3.54)$, which are averages located in the fourth category of the quadruple graduated scale categories, which indicate a (large) degree of agreement.

The researcher believes that the axis of obstacles to the content of the curriculum for mathematics ranked first for the obstacles faced by teachers of learning difficulties when teaching female students with learning difficulties to mathematics in the intermediate stage is the lack of adequate qualification for teaching mathematics for this stage and the lack of training courses that qualify them to teach mathematics at the intermediate level, as well as The researcher explains that the assessment axis obtained the least obstacles that face the teachers of learning difficulties when teaching mathematics to students with learning difficulties in the intermediate stage because of their knowledge of the appropriate assessment methods for students with learning difficulties.

The third question: Are there statistically significant differences in the obstacles facing mathematics and learning disabilities teachers in teaching mathematics to students with learning difficulties in the intermediate stage with learning difficulties programs attached to them, according to the place of teaching (normal class - outgoing room)? 
To find out if there are statistically significant differences between the averages of the responses of the study individuals about the obstacles that face female teachers of mathematics and learning difficulties teachers in teaching mathematics to students with learning difficulties in the intermediate level attached to the learning difficulties programs, depending on the place of teaching; An Independent Sample T-Test was used, as shown in Table No. (19), as follows:

Table No. (7)

The results of the t-test for two independent samples of the differences between the average responses of the study members towards the obstacles they face according to the variable of the place of teaching

\begin{tabular}{|c|c|c|c|c|c|c|}
\hline Dimensions & $\begin{array}{c}\text { training } \\
\text { place }\end{array}$ & $\begin{array}{c}\text { the } \\
\text { number }\end{array}$ & $\begin{array}{c}\text { Arithmetic } \\
\text { average }\end{array}$ & $\begin{array}{l}\text { standard } \\
\text { deviation }\end{array}$ & $\begin{array}{c}\mathbf{T} \\
\text { value }\end{array}$ & $\begin{array}{c}\text { Indication } \\
\text { level }\end{array}$ \\
\hline \multirow{2}{*}{$\begin{array}{c}\text { School and } \\
\text { organizational } \\
\text { obstacles }\end{array}$} & $\begin{array}{l}\text { A teacher } \\
\text { with learning } \\
\text { difficulties in } \\
\text { the resource } \\
\text { room }\end{array}$ & 71 & 3.40 & 0.52 & \multirow[t]{2}{*}{1.087} & \multirow[t]{2}{*}{0.278} \\
\hline & $\begin{array}{l}\text { Mathematics } \\
\text { teacher in the } \\
\text { regular class }\end{array}$ & 169 & 3.47 & 0.43 & & \\
\hline \multirow{2}{*}{$\begin{array}{l}\text { Curriculum } \\
\text { content } \\
\text { obstacles for } \\
\text { mathematics }\end{array}$} & $\begin{array}{c}\text { A teacher } \\
\text { with learning } \\
\text { difficulties in } \\
\text { the resource } \\
\text { room }\end{array}$ & 71 & 3.54 & 0.46 & \multirow[t]{2}{*}{0.063} & \multirow[t]{2}{*}{0.950} \\
\hline & $\begin{array}{l}\text { Mathematics } \\
\text { teacher in the } \\
\text { regular class }\end{array}$ & 169 & 3.54 & 0.41 & & \\
\hline \multirow[t]{2}{*}{$\begin{array}{c}\text { Evaluation } \\
\text { Obstacles }\end{array}$} & $\begin{array}{c}\text { A teacher } \\
\text { with learning } \\
\text { difficulties in } \\
\text { the resource } \\
\text { room }\end{array}$ & 71 & 3.35 & 0.46 & \multirow[t]{2}{*}{1.065} & \multirow[t]{2}{*}{0.288} \\
\hline & $\begin{array}{l}\text { Mathematics } \\
\text { teacher in the } \\
\text { regular class }\end{array}$ & 169 & 3.43 & 0.51 & & \\
\hline $\begin{array}{l}\text { Obstacles to } \\
\text { appropriate } \\
\text { teaching and }\end{array}$ & $\begin{array}{c}\text { A teacher } \\
\text { with learning } \\
\text { difficulties in }\end{array}$ & 71 & 3.40 & 0.66 & 2.896 & 0.004 \\
\hline
\end{tabular}




\begin{tabular}{|c|c|c|c|c|c|c|}
\hline Dimensions & $\begin{array}{l}\text { training } \\
\text { place }\end{array}$ & $\begin{array}{c}\text { the } \\
\text { number }\end{array}$ & $\begin{array}{c}\text { Arithmetic } \\
\text { average }\end{array}$ & $\begin{array}{l}\text { standard } \\
\text { deviation }\end{array}$ & $\begin{array}{c}\mathbf{T} \\
\text { value }\end{array}$ & $\begin{array}{c}\text { Indication } \\
\text { level }\end{array}$ \\
\hline \multirow[t]{2}{*}{$\begin{array}{l}\text { training } \\
\text { methods }\end{array}$} & $\begin{array}{l}\text { the resource } \\
\text { room }\end{array}$ & & & & & \\
\hline & $\begin{array}{l}\text { Mathematics } \\
\text { teacher in the } \\
\text { regular class }\end{array}$ & 169 & 3.14 & 0.62 & & \\
\hline \multirow{2}{*}{$\begin{array}{l}\text { The total } \\
\text { score for the } \\
\text { handicaps }\end{array}$} & $\begin{array}{c}\text { A teacher } \\
\text { with learning } \\
\text { difficulties in } \\
\text { the resource } \\
\text { room }\end{array}$ & 71 & 3.42 & 0.45 & \multirow[t]{2}{*}{0.484} & \multirow[t]{2}{*}{0.629} \\
\hline & $\begin{array}{l}\text { Mathematics } \\
\text { teacher in the } \\
\text { regular class }\end{array}$ & 169 & 3.40 & 0.37 & & \\
\hline
\end{tabular}

It is clear from Table No. (7) that there are no statistically significant differences between the average responses of the study members about the total degree of obstacles facing the teachers of mathematics and the teachers of learning difficulties in teaching mathematics to students with learning difficulties in the intermediate stage attached to the learning difficulties programs and its subdimensions represented In (School and Organizational Obstacles - Curriculum Content Obstacles for Mathematics - Assessment Obstacles) according to the variable of the place of teaching, where the significance level value for the axes, respectively $(0.278,0.950,0.288)$, and the total score of the axis $(0.629)$, all of which are greater than $(0.05)$ That is, it is not statistically significant, and the previous result indicates the convergence of the responses of the mathematics and learning disabilities teachers around those obstacles.

The researcher attributes this result to the agreement of the sample members of mathematics and learning disabilities teachers that school and organizational obstacles, curriculum content obstacles for mathematics, and assessment obstacles are the most obstacles they face while teaching mathematics to students with learning difficulties in the intermediate stage. 
Fourth question: Are there statistically significant differences in the obstacles that mathematics and learning difficulties teachers face in teaching mathematics to female students with learning difficulties in the intermediate stage to which learning difficulties programs are attached, depending on the place of teaching (years of experience)?

- Differences according to the variable years of experience:

And to find out if there are statistically significant differences between the averages of the responses of the study members about the obstacles that mathematics teachers face and the teachers of learning difficulties in teaching mathematics to students with learning difficulties in the intermediate stage to which the learning difficulties programs are attached, according to the variable years of experience; The Kruskall-Wallis test was used; This is due to the unequal categories of years of experience variable, as shown in Table No. (20), as follows:

Table No. (8)

The results of the Kruskall-Wallis test for differences between the average responses of Study individuals towards the obstacles they face according to the variable years of experience

\begin{tabular}{|c|c|c|c|c|c|}
\hline Dimensions & $\begin{array}{c}\text { Years of } \\
\text { Experience }\end{array}$ & $\begin{array}{c}\text { the } \\
\text { number }\end{array}$ & $\begin{array}{c}\text { average } \\
\text { rank }\end{array}$ & $\begin{array}{c}\text { chi-square } \\
\text { value }\end{array}$ & $\begin{array}{c}\text { Indication } \\
\text { level }\end{array}$ \\
\hline \multirow{3}{*}{$\begin{array}{c}\text { School and } \\
\text { organizational } \\
\text { obstacles }\end{array}$} & $\begin{array}{c}\text { 5years and } \\
\text { under }\end{array}$ & 31 & 144.55 & \multirow{3}{*}{7.537} & \multirow{3}{*}{0.023} \\
\hline & 10-6years & 84 & 106.47 & & \\
\hline & $\begin{array}{c}\text { 11years and } \\
\text { over }\end{array}$ & 125 & 123.96 & & \\
\hline \multirow{3}{*}{$\begin{array}{l}\text { Curriculum } \\
\text { content } \\
\text { obstacles for } \\
\text { mathematics }\end{array}$} & $\begin{array}{l}\text { 5years and } \\
\text { under }\end{array}$ & 31 & 139.63 & \multirow{3}{*}{3.995} & \multirow{3}{*}{0.136} \\
\hline & 10-6years & 84 & 111.10 & & \\
\hline & $\begin{array}{c}\text { 11years and } \\
\text { over }\end{array}$ & 125 & 122.07 & & \\
\hline \multirow{3}{*}{$\begin{array}{c}\text { Evaluation } \\
\text { Obstacles }\end{array}$} & $\begin{array}{c}\text { 5years and } \\
\text { under }\end{array}$ & 31 & 125.89 & \multirow{3}{*}{0.505} & \multirow{3}{*}{0.777} \\
\hline & 10-6years & 84 & 122.83 & & \\
\hline & $\begin{array}{c}\text { 11years and } \\
\text { over }\end{array}$ & 125 & 117.60 & & \\
\hline $\begin{array}{l}\text { Obstacles to } \\
\text { appropriate }\end{array}$ & $\begin{array}{l}\text { 5years and } \\
\text { under }\end{array}$ & 31 & 169.40 & 18.288 & 0.000 \\
\hline
\end{tabular}




\begin{tabular}{|c|c|c|c|c|c|}
\hline Dimensions & $\begin{array}{c}\text { Years of } \\
\text { Experience }\end{array}$ & $\begin{array}{c}\text { the } \\
\text { number }\end{array}$ & $\begin{array}{c}\text { average } \\
\text { rank }\end{array}$ & $\begin{array}{c}\text { chi-square } \\
\text { value }\end{array}$ & $\begin{array}{c}\text { Indication } \\
\text { level }\end{array}$ \\
\hline \multirow{2}{*}{$\begin{array}{l}\text { teaching and } \\
\text { training } \\
\text { methods }\end{array}$} & 10-6years & 84 & 117.35 & & \\
\hline & $\begin{array}{l}\text { 11years and } \\
\text { over }\end{array}$ & 125 & 110.49 & & \\
\hline \multirow{3}{*}{$\begin{array}{l}\text { The total } \\
\text { degree of } \\
\text { handicaps }\end{array}$} & $\begin{array}{c}\text { 5years and } \\
\text { under }\end{array}$ & 31 & 153.05 & \multirow{3}{*}{7.841} & \multirow{3}{*}{0.020} \\
\hline & 10-6years & 84 & 114.94 & & \\
\hline & $\begin{array}{l}\text { 11years and } \\
\text { over }\end{array}$ & 125 & 116.16 & & \\
\hline
\end{tabular}

It is clear from Table No. (8) that there are statistically significant differences between the averages of the responses of the study members about the total degree of obstacles facing the mathematics teachers and the teachers of learning difficulties in teaching mathematics to students with learning difficulties in the intermediate stage attached to the learning difficulties programs and its subdimensions represented in (School and Organizational Obstacles - Obstacles to appropriate teaching and rehabilitation methods) according to the variable years of experience, in favor of female teachers with experience (5) years or less, with an average of 144.55 for school and organizational obstacles, with an average of (169.40) for obstacles with appropriate teaching and rehabilitation methods, and with an average of 153.05 ) for the total degree of handicaps.

The researcher attributes this result to the fact that the female mathematics teachers and the learning difficulties teachers whose years of experience are (5) years or less agree to a greater degree on the obstacles they face in teaching mathematics to female students with learning difficulties in the intermediate stage to which the learning difficulties programs and their sub-dimensions represented in (obstacles). School and organizational - obstacles to teaching methods and appropriate rehabilitation) due to their lack of practical experience, so the obstacles appear clear during the teaching process. 


\section{Summary of findings and recommendations}

\subsection{The results:}

The study reached several results, the most important of which are the following:

1. There is great agreement among mathematics teachers on the obstacles they face when teaching mathematics to students with learning difficulties for the intermediate stage to which the learning difficulties programs are attached in the regular semester, where school and organizational obstacles come in the first place, followed by the obstacles of the curriculum content for mathematics, and in the third place. Assessment obstacles come, and in the end, come the obstacles of teaching methods and appropriate rehabilitation as the least obstacles that mathematics teachers face when teaching mathematics to students with learning difficulties for the intermediate stage attached to the learning difficulties programs in the regular class.

2. There is great agreement among teachers of learning difficulties on the obstacles they face when teaching mathematics to students with learning difficulties for the intermediate stage to which the learning difficulties programs are attached to the resource room, where the obstacles related to the curriculum content of mathematics come in the first place, followed by school and organizational obstacles, and in third place Obstacles to teaching methods and appropriate rehabilitation come, and finally, evaluation obstacles come as the least obstacles that teachers of learning difficulties face when teaching mathematics to students with learning difficulties for the intermediate stage to which the learning difficulties programs are attached to the resource room.

3. There are no statistically significant differences between the averages of the responses of the study members about the total degree of obstacles facing mathematics teachers and learning difficulties teachers in teaching mathematics to students with learning difficulties in the intermediate stage attached to learning difficulties programs and their sub-dimensions represented in (school and organizational obstacles - obstacles Curriculum content for mathematics assessment constraints) according to the teaching location variable. 
4. There are statistically significant differences at the level (0.01) between the average responses of the study members about the obstacles of appropriate teaching and rehabilitation methods that mathematics teachers face and teachers of learning difficulties in teaching mathematics to students with learning difficulties in the intermediate stage to which the learning difficulties programs are attached, according to the variable of the place of teaching, in favor of teachers of learning difficulties.

5. There are statistically significant differences between the averages of the responses of the study members about the total degree of the obstacles facing the teachers of mathematics and the teachers of learning difficulties in teaching mathematics to students with learning difficulties in the intermediate stage attached to the learning difficulties programs and their sub-dimensions represented in (school and organizational obstacles - road obstacles Teaching and appropriate qualification) according to the variable years of experience, in favor of female teachers who have experience (5) years or less.

6. There are no statistically significant differences between the averages of the respondents of the study members from the teachers about the obstacles (curriculum content for mathematics - assessment) according to the different years of experience variable.

\subsection{Recommendations:}

1. Redistribution of female students within regular classes in a way that allows mathematics teachers to share some elements of the lesson with female students with learning difficulties, as the results showed that the density of the number of female students limits their ability to do so.

2. Material and moral stimulation for sports and learning difficulties teachers who work in schools with learning difficulties programs attached, as the results showed that the weakness of those incentives is one of the obstacles they face.

3. Increasing the time allocated to students with learning difficulties in the resource room, 
As the results showed that, the lack of time available to them weakens the process of deepening learning difficulties teachers in the scientific material.

4. Reconsidering the mathematics curriculum for the intermediate stage to suit the students with learning difficulties in terms of content size and ease, as the results revealed that the curriculum's density and difficulty hinder teachers from explaining the lesson in detail to students with learning difficulties in the regular classroom.

5. The necessity of having a special mechanism for evaluating female students with learning difficulties for mathematics, as the results showed that not providing such a mechanism is one of the obstacles they face during the process of evaluating female students.

6. Clarify the essay questions in the mathematics test as they are read by students with learning difficulties, as the results showed that the assay method is not suitable for students with learning difficulties.

7. Providing aids that help students with learning difficulties to understand the material more, such as (visual and audio effects), as the results showed that the lack of such aids is one of the obstacles facing the teachers.

8. Rehabilitation of the general education teacher and to be aware of the teaching of students with learning difficulties in the intermediate stage, as the results showed that their lack of knowledge of teaching students with learning difficulties in the regular classroom.

9. Holding training courses and workshops to support the lack of qualification of mathematics teachers and teachers of learning difficulties, as the results showed that the lack of such courses is one of the obstacles that female teachers face.

\subsection{Suggestions:}

In light of the results that have been reached, the researcher presents some recommendations, which she hopes will contribute to enriching the educational field in that field:

1. Conducting a study dealing with the obstacles to teaching mathematics for female students with learning difficulties in other states and other regions. 
2. Conducting a study dealing with proposed solutions to the obstacles to teaching mathematics among female students with learning difficulties in the intermediate stage.

3. Conducting a study dealing with a proposed conception to develop the process of teaching mathematics for female students with learning difficulties in the intermediate stage.

4. Conducting a study dealing with the effectiveness of a proposed training program on developing the teaching skills of mathematics teachers in middle school schools with learning difficulties programs in the regular semester. Conducting studies dealing with the extent of general education teachers' knowledge of teaching students with learning difficulties at various educational levels.

\section{References:}

- Aba Hussein, Wedad, and Hussein, Rana. (2016). The level of application of learning difficulties teachers in the intermediate and secondary stages of participatory teaching. Journal of Special Education and Rehabilitation: The Institution for Special Education and Rehabilitation, Volume 3, Issue 11, 165-200.

- Abu Samaha, Kamel (2009). Learning disabilities. Journal of Education, 115 (24).

- Abu Nyan, Ibrahim (2015). Learning disabilities, teaching methods and cognitive strategies. 2nd floor, Riyadh: Academy of Special Education.

- General Administration of Special Education (1436-1437 AH). The regulatory guide for special education. Kingdom of Saudi Arabia, Ministry of Education.

- The General Administration of Education in the Riyadh region, special education institutes and programs for girls in Riyadh (1438-1439 AH). Statistics of learning difficulties programs for the intermediate stage in the Riyadh region. Ministry of Education (General Education).

- Al-Battal, Zaid (2013). Homework problems for students with learning difficulties and their peers with normal students. Education and Psychology Letter, (42), 30-57. 
- Batayneh, Mohammed and Al-Rashdan, Ahmed (2015). learning difficulties. 2nd floor, Amman: Dar Al Masirah for Publishing and Distribution.

- Peter, Peter (2009). Teaching children with learning difficulties. 1st floor, Amman: Dar Al Masirah for Publishing and Distribution.

- Al-Thubaiti, Fawzia (2011). Determining the difficulties of solving verbal mathematical problems among the fourth grade students from the point of view of mathematics teachers and supervisors in the city of Taif. Master's Thesis, Umm Al-Qura University, Makkah Al-Mukarramah.

- Al-Juhani, Salman and Al-Zari, Nayef (2014). Obstacles to the use of teaching aids by teachers with learning disabilities in teaching reading. Specialized International Educational Journal, Vol. 3, p. (10), 53-62.

- Hafez, Nabil (2008). Learning difficulties and remedial learning. 1st floor, Egypt: Anglo-Egyptian Library.

Al-Harbi, Muhammad, and Al-Moatham, Khaled. (2013). Problems of junior mathematics teachers in the Kingdom of Saudi Arabia from the point of view of their educational supervisors. Journal of Educational Sciences: King Saud University - College of Education, Volume 25, Volume 2, 263-301.

- Hassan, Abdel Hamid Saeed (2009). A comparative study of social skills among children with learning difficulties and normal children in the Sultanate of Oman. Umm Al-Qura University Journal of Educational and Psychological Sciences Saudi Arabia, 1(1), 112-69.

- Abdul Gafoor K. \& Kurukkan, Abidha. Learner and Teacher perception on Difficulties in Learning and Teaching Mathematics: Some Implications. National Conference on Mathematics Teaching- Approaches and Challenges (2015)

- Bottage, B. (2013). A comparison of two approaches for teaching complex. Authentic mathematics problems to adolescents in remedial math classes. ERIC EJ 571249.

Brown, G., Quinn, R. J. (2006). Algebra Students' Difficulty with Fractions: an Error Analysis. Australian Mathematics Teacher. 62, (4). 
- Cawley, Parmar, Yan. (2006). Arithemitic Computation Abilities of Students with Learning Disabilities Implication of Instruction, Learning Disabilities Research and Practice, 11 (4).

Costa, Adriana, Rohde, Luis and Dorneles, Beatriz. (2015). Teaching facts of addition to Brazilian children with attention - deficit/hyperactivity disorder. Education Research and Reviews, 10 (6).

- Garfield. J. \& Ahlgren. A. (2016). Difficulties in learning Basic concepts in probability and statistics. Journal for research in mathematics education, 19 (1).

- Howell, K. W., Fox. S. L., \& Morehead, M. K. 1993. Curriculum - based evaluation: teaching and decision-making. 2nd Ed. Pacific Grove, CA: Brooks/Cole.

- Hudson. S. (2010). Improving Basic Math Skills Using Technology" (ED512698).

- Jone, James, Daniel. (2007). Learning Disabilities Foundations, Characteristics and effective teaching, Journal of Learning Disabilities, 5.

- Miller, S. (2007). Educational Aspects of Mathematics Disabilities, Journal of Learning Disabilities, 30 (1).

Montague, M. \& Applegate, B. (2000). Mathematical Problem Solving Characteristics of Middle School Students with Learning Disabilities, The Journal of Special Education, 17 (2).

Doi: $\underline{\text { doi.org/10.52133/ijrsp.v2.20.8 }}$ 